\title{
Biotech finance: A family affair
}

\author{
Financing your biotechnology company is a matter of \\ building an extended family of committed individuals.
}

\author{
Edward M. Hurwitz
}

The interactions between the investment community and biotechnology companies carry with it all the dynamics of an extended family. There are sibling rivalries, intermarriages, unfriendly divorces, eccentric uncles, and all the gossip and politics that go along with these relationships. Too often, bioentrepreneurs do not appreciate how the dynamics of this family affect the growth and success of their business.

As a former research analyst who traded hats to become CFO of a public biotechnology company, my experiences on both sides of the table have afforded me an appreciation of the networks of relationships that are critical for the successful financing of a biotechnology company. After all, it is the interactions of entrepreneurs, venture capitalists, management teams, investment bankers, research analysts, and institutional investors that enable the biotechnology industry to exist in the first place.

\section{The bioentrepreneur and the VC}

At the head of most biotechnology companies is a bioentrepreneur-an individual with patentable dreams and the conviction to turn these dreams into a commercial success. Typically, the bioentrepreneur comes from the upper echelons of academia where he or she has pioneered the frontiers of a scientific field and laid claim to the insights discovered along the way. However, this individual most often has more than technical expertise driving him or her.

Typically, bioentrepreneurs are fearless individuals who are strongly self-motivated. They loathe bureaucracy, and perhaps one of their greatest thrills is proving their skeptics wrong. This pioneering instinct is what makes them so innovative, but it is also what tends to limit their network of relationships to their technical expertise. As a result, the bioentrepreneur is often naive about the business world and therefore rarely capable of translating his or her dreams into a business plan and operating a company flying solo.

Because the bioentrepreneur is typically the most eccentric member of the family, he

Edward M. Hurwitz is vice president, chief financial officer at Affymetrix, 3380 Central Expressway, Santa Clara, CA 95051

(edward_hurwitz@affymetrix.com). must be balanced out by a more "grounded" set of relatives to be able to realize the startup dream. This is where venture capitalists come in. They offer the bioentrepreneur a way to focus in a way that will translate into commercial reality. They accomplish this by providing both capital and managerial stewardship.

Venture capitalists, sometimes referred to as "vulture capitalists," are by no means philanthropic. They take on the challenge of financing and guiding a bioentrepreneur for one simple reason-to reap huge returns. This enables them to not only pay themselves

\section{Too often, bioentrepreneurs do not appreciate how the dynamics of this family affect the growth and success of their business.}

handsomely but also allows them to pay the wealthy individuals and institutions that fund the venture capital industry.

Because their investments are high risk and require exceptional returns, VCs are tough negotiators. But at the same time, they must cultivate the trust of the bioentrepreneur and establish a working relationship with the company to shepherd it into the commercial world. Many bioentrepreneurs mistakenly interpret this interaction as a commitment from the $\mathrm{VC}$ to remain invested in the company until its ultimate commercial success. This is often not the case.

Rather, because most venture funds have investment horizons of 10 years or less-generally not enough time for a biotechnology company to bring a therapeutic product to market-the VC's investment motives are usually driven by the goal of growing a company to the point where it can find an exit strategy-a public offering or sale. At that point they can recoup their investment and go on to invest in another startup.

Depending on the required timing of a venture capitalist's exit from a biotechnology company, differing degrees of market disruption can occur. Thus, a bioentrepreneur should fully understand the objectives and timing constraints that will impact the VC's commitment to the company.
Because there is an abundance of venture money chasing relatively few great ideas, VCs tend to be an extremely competitive group internally. Each fund has its own written rules that include how much it will invest, when in the company's life cycle it will invest, whether it requires board representation to invest, and when and how it will liquidate an investment.

In addition to these written rules, the biotechnology venture community also has a set of unwritten rules that result from the competitive dynamics of the industry. The most important of these delineates who gets to co-invest with the "seed" VC-the VC that initially finds and manages the emerging biotechnology company.

Because certain VCs will frequently invest together, whereas others will invest in competing companies in the same niche, understanding the unwritten rules is essential to optimizing the financing of the company in subsequent rounds. For example, because several investment banks have VC funds, choosing a seed venture capitalist with a history of co-investing with a VC affiliated with an investment bank can impact the underwriting team at the time of an IPO. For these reasons, a bioentrepreneur must pick his or her seed VC with a much longer-term view than simply the immediate dollars in the bank.

\section{The senior management team}

While the typical genesis of a biotechnology company is the meeting of entrepreneur and $\mathrm{VC}$, the success of that company relies more often on the senior management team than on the technology itself. This is not to say that successful companies do not need good technologies or products, but rather that the differentiating feature of whether that product or technology will win in the marketplace depends on how it is managed.

While there is no definitive resumé for each member of the senior management team, there is a recipe of complementary talents that must be present for a company to flourish. Besides the entrepreneur or his chief scientific counterpart-whose primary role on this team is to espouse the dream and generate the vision for the company-the other senior management members include a strategist, a tactician, and a financier. Because these jobs require special skills, there tends to be a relatively small pool of individuals capable of han- 
dling these responsibilities. In fact, many of these individuals have worked together in different capacities in past "lives," and given the dynamic nature of the industry, many are likely to work together again in the future.

The strategist's primary responsibility is to identify commercial opportunities and position the company to participate in them. Strategists are typically experienced managers from the pharmaceutical industry-often with a research or marketing background. A good strategist will not only know the products and technology, but also the competitive landscape and the network of people affiliated with them.

The tactician is needed to ensure day-today operations run smoothly, allowing milestones to be reached in pursuit of a commercial strategy. The tactician is typically an experienced manager with product and project management expertise relevant to the particular company's technology platform. A good tactician will have brought a drug or other product to market, and thereby knows the ins-and-outs of clinical trials, US Food and Drug Administration reviews, and marketing launches.

Finally, a financier is required who is familiar with the workings of the venture and public investment communities to ensure access to capital and to do everything possible to assure a rising stock price. Because most biotechnology companies lose money, this individual needs to have strategic financial skills as well as operational ones. This is why most biotechnology financiers come from the venture or investment banking sector rather than the accounting world. Thus, a good biotechnology CFO will have a strong understanding of "the Street" as well as the strategic and operating needs of the company.

\section{The investment banker}

In addition to providing the coveted forums that bring investors and companies together at conferences like H\&Q's Life Sciences meeting, investment bankers play an important role in the industry. They are the ever-confident, soft-spoken beacons of enthusiasm whose "pitch" typically includes a promise to deliver both cheap capital and impactful research coverage. In their traditional role as equity financiers, most investment bankers can be viewed as somewhat interchangeable, as the success of a biotechnology financing has much more to do with the market and the research analyst than the investment banker himself.

Traditionally, investment bankers, like VCs, operate by a set of objectives and rules. It should surprise no one that his or her primary objective is to earn a large return on investment - in the form of a hefty fee on a transaction. While the formal written and informal unwritten rules of investment banking are different from those of venture capital, they are both influenced by personalities and perceptions.

For example, different firms have very different policies about whether they will participate in a deal if they are not on the "left of the cover." In other words, they must be the lead investment banker and manage the other underwriters, or they will not participate. This position is coveted because it brings status and power, which comes from controlling the way the fees are split among the underwriters and from "running the book"-determining which investors interested in buying the deal actually get shares.

Running the book in a strong marketfor a "hot" deal-allows an underwriter to reward his best institutional clients with an

\section{This industry has found that what it is really investing in is people: individuals who have the capacity make things happen in the face of adversity.}

allocation of stock certain to make the client money at the IPO. In a "cold" deal, the book manager must work much harder for his or her money because he or she must convince others to buy in. The risk for the investment bank is high, because if the deal is done below the announced range in the prospectus-or not done at all-it is a black mark on the firm's capabilities.

These unwritten rules have more impact on a company's stock than most management teams and investors realize. The investment bank's "gross spread" is the fee the bank collects as a percentage of the total amount raised through the IPO. Because this fee is subdivided into the underwriting fee, the management fee, and the selling concession, choosing a lead underwriterand understanding how they share in the economics of the deal-can make a big difference in motivating banks and their analysts.

One of the more creative roles an investment bank can have is to serve as a financial strategist. In most cases, this means serving as an advisor during a merger or acquisition transaction. Here the banker not only opens the door to both buyers and sellers, but he or she can do the "heavy lifting" when it comes to establishing valuation and smoothing out rough spots in the negotia- tions. In this capacity, the biotechnology investment banking community is a very small circle. There are only a handful of veterans with access to the heads of the pharmaceutical industry who can either propose a merger or acquire biotechnology companies at will. Getting to know this inner circle of bankers is critical when companies are looking for an exit strategy.

\section{The research analyst}

The biotechnology research analyst has perhaps the most interesting, and at the same time, the most difficult job in the investment banking industry. The interesting part of the job comes from the intellectual challenge of sorting through infinite amounts of information and disparate opinions to distill out an investment conclusion for a particular company. The job is a privileged one where time and financial resources typically permit the analyst and his or her research team to visit directly with management and attend the industry events - analyst briefings, scientific sessions, and FDA meetings impacting the company.

The difficult part of the job is being right both in absolute and relative terms. Being right in absolute terms no easy task. Drug development is inherently a complex and risky business as unpredictable as human biology itself. This uncertainty is magnified by the fact that data presented publicly is typically done so with extreme care to "spin" the best case for the product. Thus, over the course of the development of a drug, there is rarely sufficient information for an analyst to be certain. Rather, an analyst must work with the available data, combined with innuendo, rumor, and gut feelings to make a judgment call.

Because the research analyst's job is to make judgment calls, the influence of the investment banking relationship can often impact this judgment-making a hard job even harder. For example, while there is no written rule that an analyst from a company's investment bank must rate a client's stock a "buy," rarely will this not be the case. The reason for this is twofold. First, the investment bank is often chosen based on the research analyst's enthusiasm for the company-thereby nearly ensuring "bullish" coverage. Second, the research analyst, whether directly or indirectly, often shares in the fees generated by banking transactions related to the company. This can create a situation where the analyst has a financial incentive to remain positive about a company even when its prospects no longer deserve enthusiasm.

At the largest investment banks, underwriting fees are typically a much less important component of analysts' compensation, making it easier-but by no means 
easy - for analysts at these firms to be more objective. At smaller banks-historically, the group that has done the majority of biotechnology financing - the conflict can be more problematic, as the analyst typically has a more direct interest in the banking fees.

Different analysts deal with this conflict in different ways, but an almost universal tactic is that the analysts will change their "tone" in promoting a company's stock. Sometimes this change is discernible in their written remarks about a stock, but most often it is discernible in how they speak about the stock-this too differs depending on their audience. Consequently, depending on whom an analyst is speaking with and the relationship they have developed, the message can be quite different. This is why having a relationship built on trust with an analyst is critical for an institutional investor to get a feel for what an analyst is really thinking.

\section{The institutional investor}

There are three basic flavors of institutional investor in biotechnology stocks - the "value" player, the "short" seller, and the "momentum" player. Both the value and short investor need and use momentum players to make money in this sector.
Momentum players are the generalists who manage growth-oriented funds but have no or only limited focus on healthcare or biotechnology stocks. As other investment alternatives lose their attractiveness, momentum investors have the ability to move large sums of capital into the biotechnology sector even though they have, at best, only a basic understanding of the investment issues facing the stocks they buy. Momentum buyers are also generally necessary for a biotech-financing window to open and for the value and short investors to take profits or build positions depending on which way momentum is swinging.

When one strips the momentum investor out of the investment picture, one is left with the value shoppers and short sellers. The short seller will typically sell shares to the momentum buyer as a stock rises, while a value shopper will pick up bargains from the momentum investor as he flees to greener pastures.

While there is tension between value investors and short-fund managers, there is also a strong sense of camaraderie as these investors, along with the research analysts, form the core of the biotechnology investment community. It is this group that sees each other regularly at investment confer- ences, medical sessions, and FDA panel meetings. These investors are often the first to get calls directly from analysts and their sales forces, thereby becoming privy to the unwritten opinions and gossip of the industry as well as helping to generate it.

\section{Conclusions}

From the set of profiles described above, it may surprise many bioentrepreneurs that millions of dollars change hands in this industry based on people issues rather than on a cold objective analysis. To be sure, the analytic aspect of the industry is well supported-millions of dollars are spent on due diligence.

But at the end of the day, when one is forced to make a decision, this industry has found that what it is really investing in is people: individuals who have the capacity to make things happen in the face of adversity. This characteristic is perhaps the key feature of the biotechnology "family" that makes this sector so powerful. In a little over two decades, the biotechnology industry has revolutionized healthcare-despite the openings and closings of the funding window. Whether this family remains healthy depends on the continued contributions of all its members. 